\author{
Paper Submitted to \\ Journal of Construction and Building Materials
}

\title{
Remote Sensing Application in Surveying Statewide Asphalt Pavement Aggregate Stockpile Inventory
}

a 201 More Hall, Department of Civil and Environmental Engineering, University of Washington, Seattle, WA, 98105. E-mail: ashtiani@uw.edu.

* Corresponding Author: Milad Zokaei Ashtiani

b 201 More Hall, Department of Civil and Environmental Engineering, University of Washington, Seattle, WA, 98105. E-mail: stmuench@uw.edu.

c 201 More Hall, Department of Civil and Environmental Engineering, University of Washington, Seattle, WA, 98105. E-mail: dshean@uw.edu.

ORCiD: 0000-0002-2851-4025

Phone: (617) 955-7875

Email: ashtiani@uw.edu 


\section{Abstract}

2 This study introduces a remote sensing application using satellite imagery to survey a network3 scale aggregate stockpile inventory. First, a real scale aggregate quarry site was surveyed using a 4 small Unmanned Aerial Vehicle (sUAV) to produce digital terrain models that enabled analysis of 5 aggregate pile geometry. Second, a lab experiment was designed and performed to validate the 6 applicability of close-range Structure from Motion (SfM) photogrammetry for measuring 7 aggregate piles' physical properties such as volume and density. The other part of the lab 8 experiment delved into direct measurement of aggregate density under varying compaction efforts. 9 These experimental results, in conjunction with some simplifying assumptions, enabled the 10 calculation of aggregate stockpile volumes and estimated weights from satellite imagery. We 11 estimated that an inventory of 4.4 and 1.1 million metric tons of crushed aggregates and Reclaimed 12 Asphalt Pavement (RAP), respectively, stockpiled in Washington State for asphalt production in 13 2017. The merit of producing such database was further showcased in an example on the economic 14 and environmental impacts of material transportation. We approximated that hauling aggregates 15 from quarry plants to construction sites within Washington State incurs a cost of about $\$ 50$ 16 thousand to over $\$ 4$ million, consumes about 0.25 to $20 \mathrm{TJ}$ of energy, and emits 20 to over 1,500 17 tons of $\mathrm{CO}_{2}$-eq per asphalt plant annually. 


\section{Introduction}

Construction and building materials comprise about three-quarters of raw materials consumed by weight in the U.S. [1], and this trend has been fairly consistent over the past century of rapid infrastructure growth and urbanization. Buildings and roadway construction are two major industries using these materials, mostly in the form of crushed stone, sand, and gravel. In 2018, the U.S. Geological Survey (USGS) reports that 2.2 billion tons of sand, gravel, and crushed stone were produced in the U.S. at a value of $\$ 25.3$ billion, out of which 970 million tons were attributed to sand and gravel (44\% concrete; $24 \%$ road base; $12 \%$ asphalt; $12 \%$ construction fill) and 1.4 billion tons to crushed stone production $(75 \%$ as construction materials, mostly for roads; $13 \%$ cement) [2]. Moreover, the U.S. Environmental Protection Agency (EPA) reported that around 70 and 15 percent of construction \& demolition debris in 2015 were generated from out of service Portland cement and asphalt concrete, respectively, totaling approximately 465 million tons value of weight [3, 4], most of which was recycled in the form of Recycled Concrete Aggregate (RCA) and Reclaimed Asphalt Pavement (RAP).

Because of their resource prevalence and availability in almost every corner of the world, crushed stone is relatively inexpensive, roughly falling in the range of $\$ 5$ to $\$ 30$ per metric ton, with a National average of \$10.6 in 2015 [5]. However, these materials are comparatively heavy with specific gravities ranging from 1.5 to over 2.5. As a result, aggregate transportation can incur as much expenditure as extraction and processing operations [6]. Depending on gas price and location, hauling processed aggregates from the point of origin (i.e. quarry) to the point of use (i.e. construction site) can cost over $\$ 0.18$ per metric ton-km, or $\$ 110$ per hour of trucking [6].

Traditional methods of estimating aggregate stockpile volumes include truck ticket records and geodetic surveys. While these approaches typically offer high accuracy, conventional surveying methods can be time-consuming and expensive to perform. In the past decade, modern surveying methods such as Structure from Motion (SfM) photogrammetry from Unmanned Aerial Vehicles (UAV) and airborne, or ground-based, Light Detection and Ranging (LiDAR) have become more affordable. Cameras can be mounted on a UAV (drone) platform to capture images systematically from different angles and distances. Close-range (terrestrial) photogrammetry using consumergrade cameras can be used for laboratory experiments given their small-scale geometry, while UAV photogrammetry surveys are ideal for site-scale field studies. Regardless of scale, automated SfM processing software can then produce high-resolution (typically $\mathrm{mm}$ to $\mathrm{cm}$ ) digital terrain models and orthoimage mosaics from these images. The terrain models can be used for stockpile volume calculation, while repeat surveys can provide volume change.

Several private companies currently perform UAV surveys of aggregate quarry plants for internal interests such as time and cost savings, on-demand inventory measurements, uninterrupted site operations, demand-supply equilibrium, and reduced human error and injury risk. While individual companies typically keep records of their stockpile inventory for project-level decision making, large-scale inventories seem nonexistent. Many recent studies have also leveraged these new technologies for volume estimation and accuracy assessment. A summary of recent research results is presented in Table 1. This table is sorted in the order of sample volume sizes. Most research in this area involves a comparative study between one traditional surveying technique (e.g. total station) or another basic method of volume approximation (e.g. truck ticket records) with more advanced and newly emerged technologies such as UAV photogrammetry or LiDAR. In general, regardless of methods deployed, the relative absolute difference in volume measurements found to be less than about $5 \%$. These studies can be broadly categorized into two areas: real-world application, and laboratory scale evaluation. 
Table 1

69 Comparison of volume estimation methods and results discussed in the literature.

\begin{tabular}{|c|c|c|c|c|}
\hline Object & Comparison & $\begin{array}{l}\text { Absolute } \\
\text { Difference }\end{array}$ & $\begin{array}{c}\text { Approximate } \\
\text { Volume }\end{array}$ & Source \\
\hline $\begin{array}{l}\text { Lab experiment on } \\
\text { plaster cone }\end{array}$ & $\begin{array}{l}\text { Close-range SfM vs } \\
\text { geodetic survey }\end{array}$ & $1.3 \%$ & $364 \mathrm{~cm}^{3}$ & [7] \\
\hline $\begin{array}{c}\text { Lab Experiment on } \\
\text { soil embankment }\end{array}$ & $\begin{array}{c}\text { Close-range SfM vs } \\
\text { lab measurements }\end{array}$ & $<2 \%$ & $3,000 \mathrm{~cm}^{3}$ & [8] \\
\hline Hay bales & $\begin{array}{c}\text { UAV vs tape } \\
\text { measure (in-situ) }\end{array}$ & $<5 \%$ & 2 to $20 \mathrm{~m}^{3}$ & [9] \\
\hline Natural hill & $\begin{array}{l}\text { Close-range SfM vs } \\
\text { geodetic survey }\end{array}$ & $1.3 \%$ & $33 \mathrm{~m}^{3}$ & [10] \\
\hline Stone heap & $\begin{array}{c}\text { Close-range SfM vs } \\
\text { geodetic survey }\end{array}$ & $5.1 \%$ & $34 \mathrm{~m}^{3}$ & [7] \\
\hline Rock dumps & $\begin{array}{l}\text { Satellite imagery vs } \\
\text { terrestrial LiDAR }\end{array}$ & $2 \%$ & $700 \mathrm{~m}^{3}$ & [11] \\
\hline Rock dumps & $\begin{array}{c}\text { Satellite imagery vs } \\
\text { GNSS }\end{array}$ & $5 \%$ & $700 \mathrm{~m}^{3}$ & {$[11]$} \\
\hline Aggregate stockpile & UAV vs truck ticket & $2.5 \%$ & $1,500 \mathrm{~m}^{3}$ & {$[12]$} \\
\hline Aggregate stockpile & UAV vs LiDAR & $<1 \%$ & $3,800 \mathrm{~m}^{3}$ & {$[13]$} \\
\hline $\begin{array}{l}\text { Aggregate } \\
\text { Stockpiles } \\
\end{array}$ & $\begin{array}{l}\text { UAV: ArcGIS vs } \\
\text { Photoscan Software }\end{array}$ & $<0.2 \%$ & 78 to $5,500 \mathrm{~m}^{3}$ & {$[14]$} \\
\hline Earthwork & $\begin{array}{l}\text { UAV vs truck } \\
\text { tickets }\end{array}$ & $2.5 \%$ & $10,500 \mathrm{~m}^{3}$ & {$[15]$} \\
\hline Aggregate stockpile & UAV vs total station & $3.4 \%$ & $11,500 \mathrm{~m}^{3}$ & {$[16]$} \\
\hline Aggregate stockpile & $\begin{array}{c}\text { UAV vs plant } \\
\text { estimate }\end{array}$ & $0.7 \%$ & $11,500 \mathrm{~m}^{3}$ & {$[16]$} \\
\hline Open pit quarry & UAV vs GPS & $1.1 \%$ & $12,700 \mathrm{~m}^{3}$ & {$[17]$} \\
\hline Earthwork & UAV vs GNSS & $1 \%$ & $17,000 \mathrm{~m}^{3}$ & {$[18]$} \\
\hline Aggregate stockpile & UAV vs LiDAR & $<3 \%$ & 43,000 to $70,000 \mathrm{~m}^{3}$ & [19] \\
\hline Aggregate stockpile & UAV vs GNSS & $2.6 \%$ and $3.9 \%$ & Unknown & [12] \\
\hline
\end{tabular}

Despite being efficient, inexpensive, and accurate, current UAV surveys are typically limited to areas of less than $1 \mathrm{~km}^{2}$. On the other hand, high-resolution satellite imagery can offer nearly global coverage with sub-meter to meter-scale resolution [11]. While it is possible to acquire stereo satellite images that can be used for 3D reconstruction (e.g. [20]), most publicly available satellite 
on stockpile area, which can then be scaled for volume estimates. Remote sensing applications involving geodetic volume calculations are limited in the aggregate stockpile literature, though they are more common in other areas of study such as glaciology to find glacier volume change (e.g. [21]), limnology to find lake and other water reservoir volumes (e.g. [22]), and forestry to find potential biomass supply (e.g. [23]). The present paper is an attempt to expand the current knowledge and technology of remote sensing applications to the construction engineering arena.

\section{Objective}

This study investigates the applicability of remote sensing methods to estimate crushed aggregate stockpile weights at different scales from laboratory to state-wide inventories. To gain insight into the geometric and physical properties (i.e. shape and density) of aggregate stockpiles, we performed UAV SfM surveys for an aggregate quarry plant and close-range SfM surveys for small-scale laboratory aggregate pile samples. Satellite imagery from Google Earth along with some simplifying assumptions were then adopted to locate stockpiles and measure their volumes in a case study of Washington State hot mix asphalt (HMA) inventory. Results from the laboratory experiments were examined to constrain the conversion of volume to weight, which was then used to validate the assumptions made to convert the volumes measured from satellite imagery technique. The outcome is a detailed spatial distribution of crushed aggregate and RAP weights between May and August of 2017 within the state of Washington. The application of such database in environmental impact assessment of materials transportation will be exemplified for the case of HMA production plants within Washington State.

\section{Methods}

This research is structured into three sections. The first section explains the experimental design of SfM photogrammetry surveys for an aggregate quarry site and a laboratory setup. The second part elaborates on how satellite images of state-wide aggregate storage sites were located and processed to calculate volumes. Lastly, we spend another section to explain the challenges involved and solutions proposed in converting volume measurements into weights.

\subsection{Structure from Motion}

$\mathrm{SfM}$ is a photogrammetric technique to reconstruct three-dimensional surface structure from two-dimensional digital images by solving for 3D object and camera position/orientation simultaneously $[10,14]$. Images can be acquired by cameras mounted on a tripod, a pole, or a UAV. When georeferenced output products are desired, Ground Control Points (GCPs) in a known coordinate system are deployed to constrain the SfM optimization. When absolute georeferencing is not required, objects with known dimensions can be situated within the field of view for subsequent scaling of point clouds. We deployed GCPs for the UAV survey of the aggregate quarry plant and scale constraints for the lab experiment.

We took advantage of the Pix4DMapper software to produce dense point clouds, 3D triangulated meshes, gridded Digital Surface Models (DSMs), and orthoimages. We manually digitized object boundaries (i.e. stockpile margins) within Pix4DMapper. Volumes were calculated using the built-in algorithms which involves fitting a planar surface to these points to approximate the base area and triangulation to calculate the volume of objects [24]. We used ESRI ArcMap for final data visualization and raster analysis. 


\subsection{Satellite imagery}

118

119

120

121

122

123

124

125

126

127

128

129

130

131

132

133

134

135

136

137

138

139

140

To complement the field and laboratory studies, we used satellite imagery to survey a representative sample population of HMA production plants in Washington State. We used Google Earth Pro software to identify these features, browse historic image records, and measure surface area and elevation (when available) for a sample of aggregate and RAP stockpiles. Details on this methodology was described elsewhere [25]. The Washington Asphalt Pavement Association (WAPA) member roster list was used as the primary source to find and locate asphalt producers, as WAPA claims to represent most of the asphalt industry within the State. In addition, we used general Google queries with keywords such as "asphalt," "aggregate quarry," "recycling," and the names of local companies.

To estimate the volume of each stockpile, we first used the 3D polygon tool from Google Earth Pro to measure base area of aggregate piles, and the default Digital Elevation Model (DEM) to estimate an average height $[7,25]$. This average height is a fraction of maximum height of the pile; for instance, in a case of a perfect cone, this fraction is equal to one-third. Since piling up crushed stones in the form of a perfect cone is practically impossible, the ratio of average to maximum height of aggregate stockpiles were assumed to be greater than 0.33 but less than 0.5 . Validity of this assumption will be examined when analyzing results of the aggregate quarry site survey. Furthermore, the Washington State Department of Transportation (WSDOT) limits the maximum height of aggregate piles to $24 \mathrm{ft}$ ( 7.3 meters), so the average height should not exceed this upper threshold in most situations [26]. Therefore, stockpiles were assumed to resemble right prisms with a base area as measured from satellite images and an average height in a range of 1 to 7.5 meters. To find the volume of each pile, average height was multiplied by base area. Details on the validity of average height assignments can be found elsewhere [25]. These volume measurements then need to be converted into weights which will be discussed later.

\subsection{Volume to weight conversion}

While volume is a common physical property measured in UAV surveys, it is useful to find weight since aggregates are most often priced, batched, and controlled by weight. Thus, it would be valuable to convert the estimated volumes to a representative weight. Piling up aggregates may cause a non-uniform distribution in air voids and moisture content which adds up to the complexity of finding an equivalent density; however, we will investigate whether a general rule of thumb applies. As Skorseth \& Selim (2000) put it, compared to bulk specific gravity, materials in stockpiles or in the back of dump trucks are very loose and have lower densities [27]. EPA Standard Volume-to-Weight Conversion Factors document outlines typical density values for a variety of materials including sand and gravel in different conditions such as dry, loose, wet, and moist [28].

According to EPA, specific gravity of gravel and sand regardless of moisture condition falls in the range of 1.5 to 1.9 and 1.4 to 2.1 , respectively. Conversion of volume to weight, therefore, relies heavily on the existing literature. However, two laboratory experiments designed in this study will help examine and validate the density values offered from the literature and publicly available documents. In that, one experiment implements SfM technique to estimate volumes of laboratory simulated aggregate piles with known weights to approximate density. The other method adopts a more traditional way of determining density by measuring the weight of aggregates required to fill a cylinder with known volume. 


\section{Data collection}

\subsection{Aggregate quarry plant}

A UAV survey was performed over an aggregate quarry located in Monroe, WA on May 20, 2019 at 11:30 AM PDT. The quarry consists mostly of crushed stone particles specifically processed for HMA production. There were a total of 9 aggregate stockpiles with varying particle sizes (from 1.5 inch $(38.1 \mathrm{~mm}$ ) to less than 0.5 inch $(12.5 \mathrm{~mm})$ ) during the survey. A UAV mission plan was designed using the Pix4DCapture mobile application. A DJI Mavic Pro Platinum UAV with 12 MP camera was used to fly at a fixed altitude of 40 meters, resulting in image Ground Sample Distance (GSD) of $1.16 \mathrm{~cm}$. The coverage area was approximately $25,500 \mathrm{~m}^{2}(170 \times 150$ meters). Roughly 400 images were acquired over a flight duration of 19 minutes, with camera orientation fixed at $80^{\circ}$.

A total of thirteen $48 \times 48$-inch "iron-cross" GCP targets were deployed around the quarry site prior to the UAV survey mission. The GCP coordinates were measured using an Emlid ReachRS Global Navigation Satellite System (GNSS) receiver mounted on a standard two-meter survey pole. The survey team performed a Real-Time Kinematic (RTK) GNSS survey with real-time corrections from the Washington State Reference Network (WSRN) through Networked Transport of RTCM via Internet Protocol (NTRIP) feed. Each GCP was occupied for one minute, offering final horizontal and vertical position accuracy of $1-3 \mathrm{~cm}$. Some GCPs near large aggregate piles, however, displayed higher error due to limited horizon coverage and multi-path phenomenon. Overall, the root mean square error of the GCP positions was $39 \mathrm{~cm}$. Geographic coordinates were recorded in WGS84. Studies have shown that deployment of 10 GCPs is sufficient for most 180 applications and will produce satisfactory accuracy/precision [15, 29]. Figure 1 shows the GCP 181 layout and UAV survey details of the quarry site.

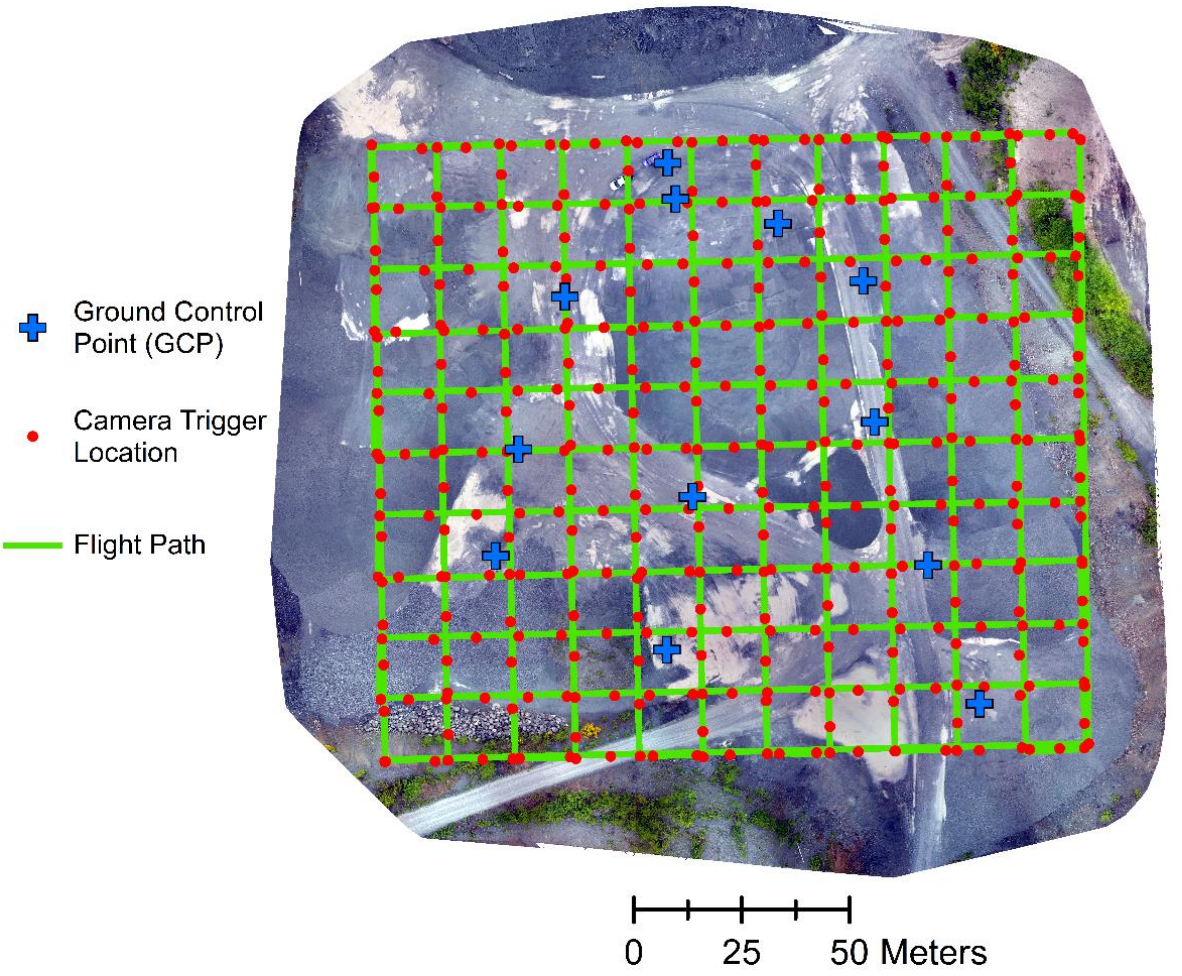

Fig. 1. UAV flight pattern and GCP locations over the aggregate quarry site. 


\subsection{Lab experiment}

Although SfM is a powerful tool for measuring volume, the property that is more critical in many real-world applications is mass or weight. The link between the two properties is density, or weight per unit volume of an object. Since there were no records available on the approximate weight of aggregate stockpiles of the quarry plant survey, a lab experiment was designed to constrain the density. Two aggregate sources were tested: 100\% passing \#4 sieve sand with a fineness modulus of 2.6, and a coarse aggregate source with no particles passing \#4 sieve and a nominal maximum aggregate size of $3 / 4$ inch $(19 \mathrm{~mm})$. Moisture content of both aggregate types were maintained as close to Saturated Surface Dry (SSD) condition as possible. Sand and gravel were purchased from Salmon Bay Sand \& Gravel company which reported bulk specific gravities of 2.6 and 2.7 , respectively.

A total of twelve close-range SfM experiments were performed in the lab, involving dumping materials over a steel-top table in increments of $50 \mathrm{~kg}$, with final pile weights of 50, 100, 150, 250, and $300 \mathrm{~kg}$. For both materials, a duplicate $300-\mathrm{kg}$ pile was considered to examine the effect of aggregate pile redistribution on volume measurements. To document final pile volumes, an average of 50 images were acquired with a Canon PowerShot SX200 IS camera for each pile from a variety of angles and distances. Since georeferencing was not necessary for this experiment setup, objects with known dimensions including three meter-sticks were used to constrain scale.

\subsubsection{Direct density measurement}

The final component of the experimental plan involved direct measurement of sand and gravel densities. A standard $4 \times 6$ inch $(101.6 \mathrm{~mm} \times 152.4 \mathrm{~mm})$ hollow plastic cylindrical container was filled with each of the aggregate types and weighed using a digital scale. Sampling occurred immediately after SfM data collection to minimize changes in moisture content. Knowing the volume and filled weight, the density of each material can be calculated. As with the field study of aggregate stockpiles, the level of compaction in the laboratory experiments was unknown, so a statistical approach to density measurements was adopted. Each time the cylinder was filled, different levels of compaction effort were applied to obtain a scatter of results for density. A total of 35 samples were tested for each aggregate type. Summary statistics such as average, range, and standard deviation were computed, offering thresholds for expected density values.

\subsection{Satellite imagery}

A total of 60 potential locations in Washington State with some sort of aggregate or RAP stockpile in 2017 were identified in satellite images. Those stockpiles were either located at asphalt plant facilities or in some cases at a processing site within immediate vicinity of an asphalt plant, as it makes economic sense to minimize truck hauling distances. Satellite image acquisition dates ranged from May to August 2017. 63\% of these locations had usable 3D terrain information in Google Earth Pro, which represented $75 \%$ of the total aggregate volumes as discovered later.

Generally, asphalt plants and aggregate processing sites pile up crushed stone in separate stockpiles based on gradation. The resolution of satellite images $(\sim 0.5 \mathrm{~m})$, however, is not fine enough to distinguish particle sizes. Aggregate gradation, thereafter, was left out as a variable in satellite imagery data collection. Other than crushed stone, RAP is most often stored within asphalt plants; however, due to its distinct black color, RAP could be differentiated from grayish colored crushed stone. It should also be noted that covered aggregate stockpiles were excluded in this study as the underlying material was unknown. Overall, a total of 759 aggregate and 67 RAP stockpiles were identified and used for subsequent analysis. 
228

Figure 2 shows a sample aggregate pile captured from Google Earth in aerial and oblique angles. The base area of this pile was measured as $1,245 \mathrm{~m}^{2}$ (Figure 2-a) with a maximum height of approximately 4.5 meters (Figure 2-b). Since the shape of this pile resembles a frustum, the average height was assumed to be 2 meters, which can be translated into an equivalent fraction of 0.44 of the maximum height. This would result in a volume of $2,490 \mathrm{~m}^{3}$. We took the same approach for all other stockpiles and the resulting data were compiled into a spreadsheet accompanied with other pieces of information such as the geographic coordinates of the site and the name of property owner (if available).

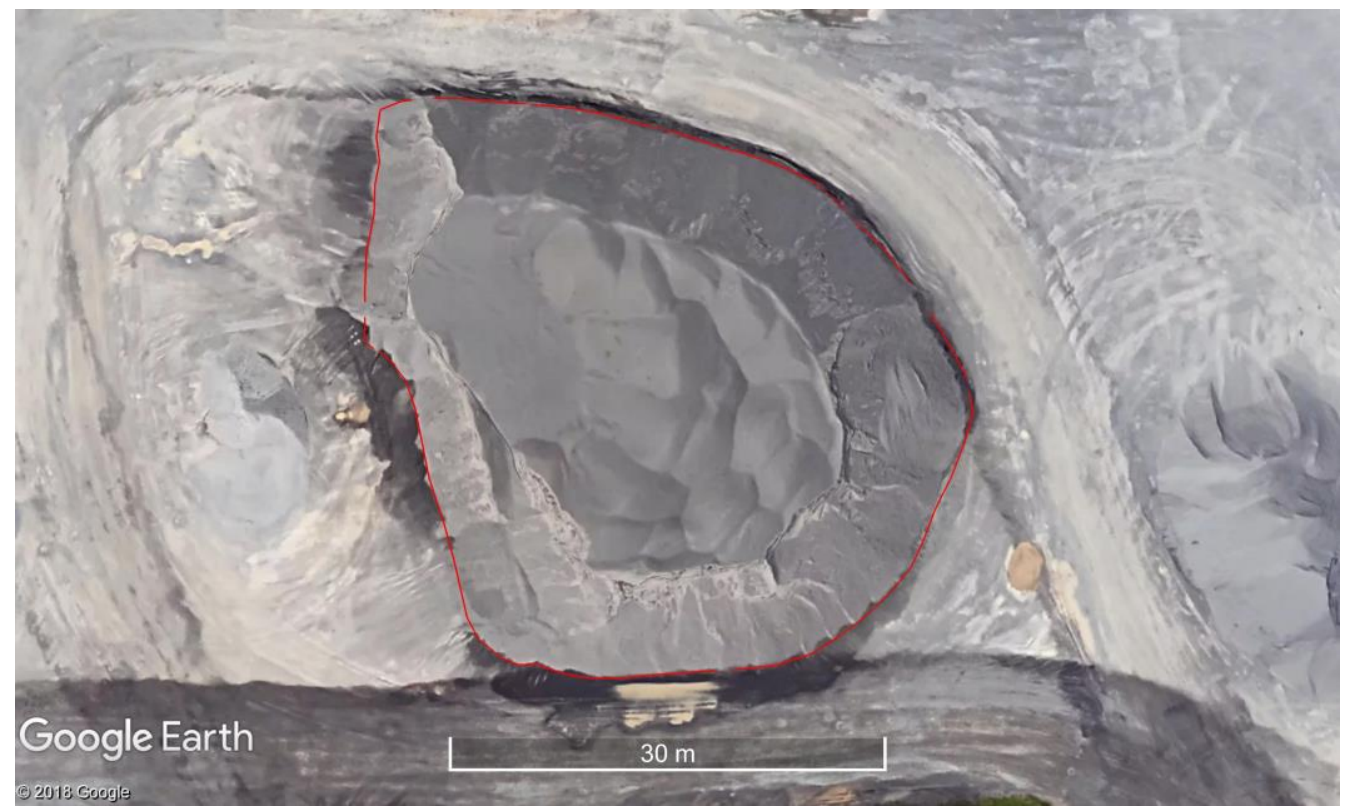

(a)

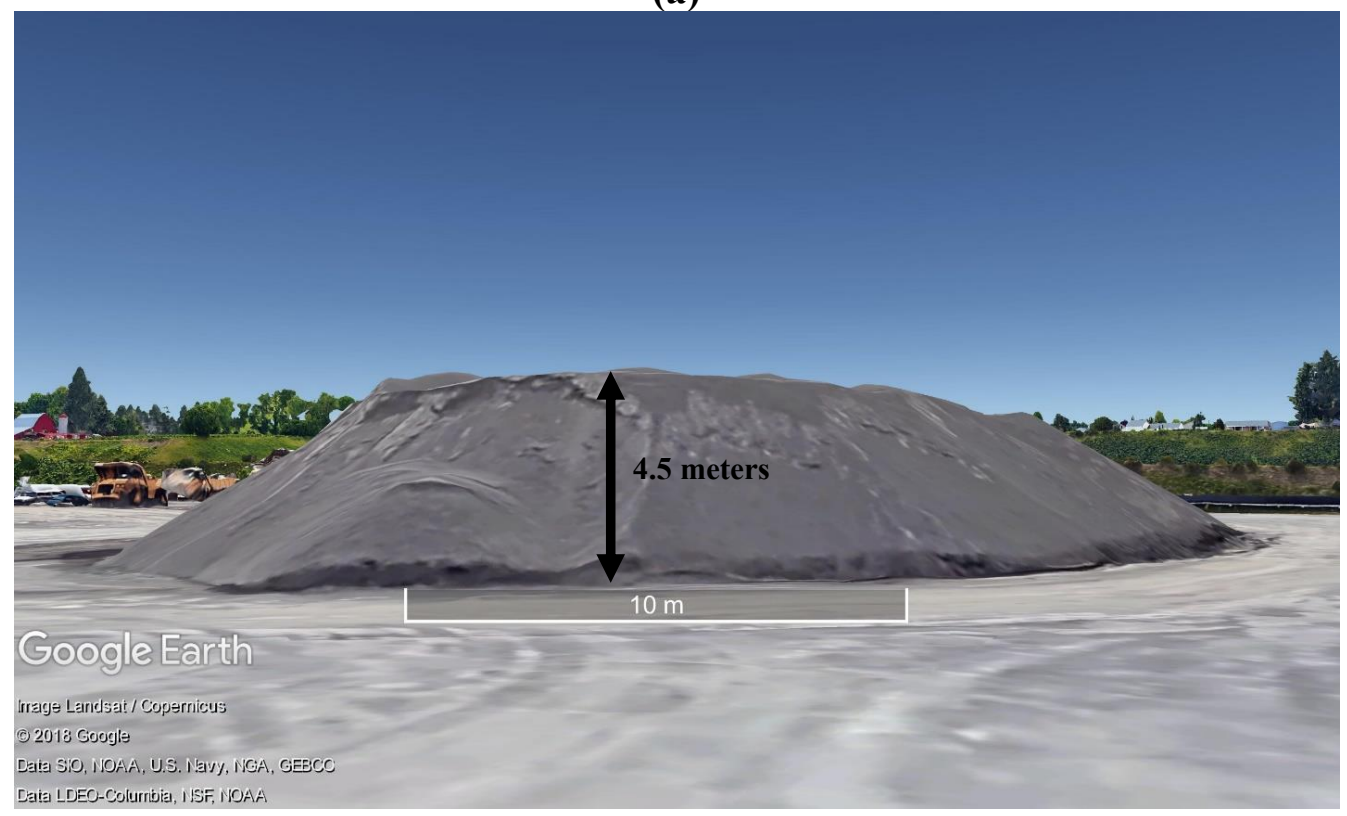

(b)

Fig. 2. A sample 3D rendering of an aggregate stockpile in Google Earth, a) in aerial and b) oblique view, showing approximate height. 


\section{Results}

\subsection{Aggregate quarry plant results}

Figure 3 shows the results for the aggregate quarry UAV survey. A total of 9 aggregate piles are identifiable in these illustrations. Elevation values are geodetic heights above the WGS84 ellipsoid. Although not clearly visible, there are some artifacts in the DSM near the margins of the survey area (e.g. pile number 9), where the number of overlapping photographs was limited. Overall, the volumes of 9 distinct stockpiles were measured totaling $87,162 \mathrm{~m}^{3}$. Table 2 summarizes the UAV mission data collection of the aggregate processing site. An average height can then be calculated when dividing volumes by their corresponding base surface area; so that knowing only the surface area, one can roughly calculate the volume (i.e. upscaling areas to volumes). The average heights of these piles range from 1.75 to 4.7 meters with the exception of pile 9 which is suspected to be influenced by artifacts and therefore eliminated from further analysis. Dividing average height by maximum height of each pile, Table 2 indicates that this ratio ranges from about 0.37 to 0.49 .

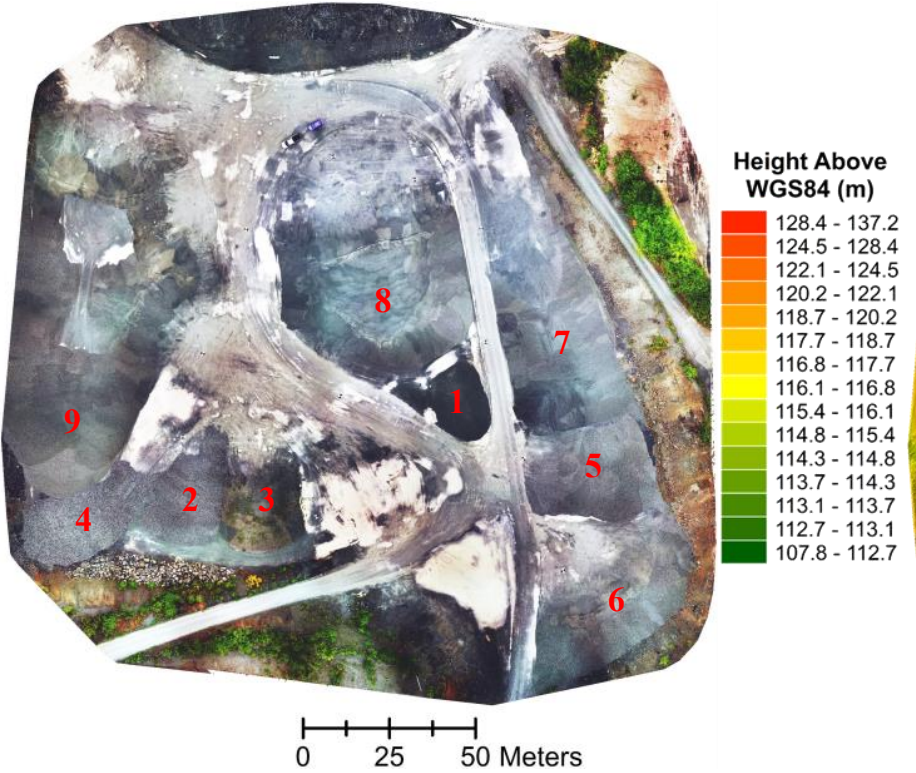

(a)

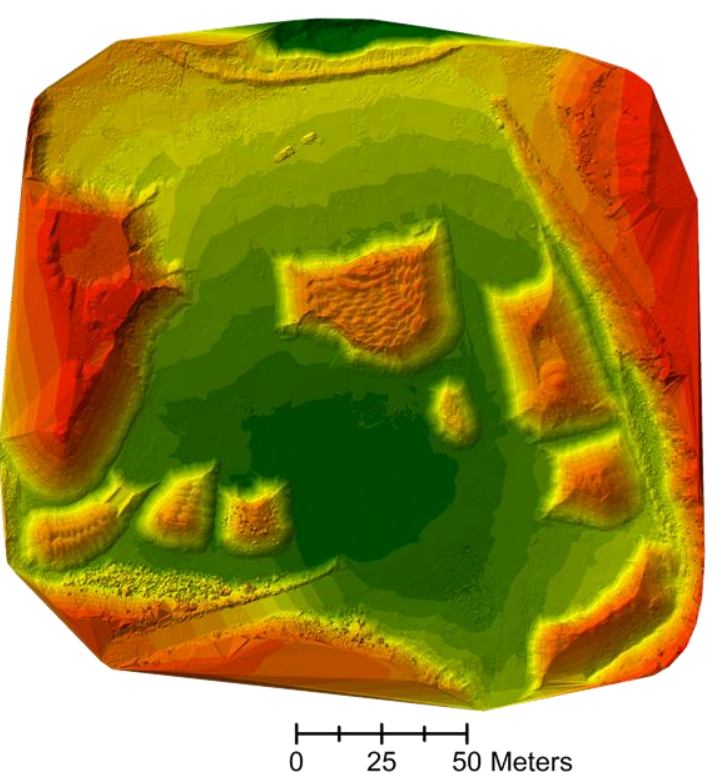

(b)

Fig. 3. Output products from SfM surveys of the aggregate quarry site showing a) an orthoimage mosaic with piles numbered in the order of their volume, and b) corresponding digital surface model (DSM).

\subsection{Lab experiment}

Raster analysis of laboratory samples resulted in DSMs and orthoimage mosaics. To exemplify, Figure 4 shows one of the two $300 \mathrm{~kg}$ sand and gravel piles from the laboratory experiment. The resolution is fine enough that the DSM for the gravel pile shows a rougher surface texture. Due to the highly controlled lab environment, the output DSM products do not show any artifacts. Table 3 is a summary of findings for volumes and their associated weight measurements. For each material, the $300-\mathrm{kg}$ sample was used as a reference to calculate percent difference of densities. For example, the $300-\mathrm{kg}$ gravel sample had a volume of $0.170 \mathrm{~m}^{3}$ and a corresponding density of $1,765 \mathrm{~kg} / \mathrm{m}^{3}$. For each smaller sample, densities were compared with this reference density, and 
relative differences were calculated which fell in a range of 0.5 to $6.0 \%$. Finally, results suggest an average density of 1,443 and $1,765 \mathrm{~kg} / \mathrm{m}^{3}$ for sand and gravel, respectively.

\subsubsection{Direct density measurement}

Figure 5 shows all density measurements with variable compaction levels and is accompanied by a picture of the test sample. The density of sand is more sporadic over a range of 1,300 to over $1,800 \mathrm{~kg} / \mathrm{m}^{3}$ while gravel densities are clustered in a tighter range of 1,550 to below $1,800 \mathrm{~kg} / \mathrm{m}^{3}$. The average densities of sand and gravel were 1,519 \pm 139 and $1,644 \pm 54 \mathrm{~kg} / \mathrm{m}^{3}$, respectively. The average density values will be used in place of the entire scatter of data when applicable. Despite not being Normally distributed, density measurements can still provide some clues on how compaction effort can influence the process of volume to weight conversion.

\subsection{Satellite imagery}

291 Summary of aggregate quarry site UAV survey.

\begin{tabular}{cccccc}
\hline ID & $\begin{array}{c}\text { Base Area } \\
\left(\mathbf{m}^{\mathbf{2}}\right)\end{array}$ & $\begin{array}{c}\text { Volume } \\
\left(\mathbf{m}^{\mathbf{3}}\right)\end{array}$ & $\begin{array}{c}\text { Average Height } \\
(\mathbf{m})\end{array}$ & $\begin{array}{c}\text { Max Height } \\
(\mathbf{m})\end{array}$ & $\begin{array}{c}\text { Average to Max } \\
\text { Height }\end{array}$ \\
\hline $\mathbf{1}$ & 301 & 676 & 2.2 & 5.2 & 0.43 \\
\hline $\mathbf{2}$ & 510 & 1,512 & 2.9 & 7.3 & 0.40 \\
\hline $\mathbf{3}$ & 494 & 1,635 & 3.3 & 8.7 & 0.38 \\
\hline $\mathbf{4}$ & 661 & 1,812 & 2.7 & 7.1 & 0.39 \\
\hline $\mathbf{5}$ & 727 & 2,648 & 3.6 & 9.9 & 0.37 \\
\hline $\mathbf{6}$ & 1,063 & 4,008 & 3.8 & 9.7 & 0.39 \\
\hline $\mathbf{7}$ & 1,528 & 6,331 & 4.1 & 10.7 & 0.39 \\
\hline $\mathbf{8}$ & 1,976 & 9,336 & 4.7 & 9.7 & 0.49 \\
\hline
\end{tabular}




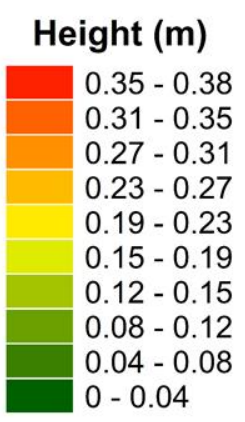

Height ( $\mathrm{m}$ )

\begin{tabular}{|l|}
$0.24-0.27$ \\
$0.21-0.24$ \\
$0.19-0.21$ \\
$0.16-0.19$ \\
$0.13-0.16$ \\
$0.11-0.13$ \\
$0.08-0.11$ \\
$0.05-0.08$ \\
$0.03-0.05$ \\
$0-0.03$
\end{tabular}

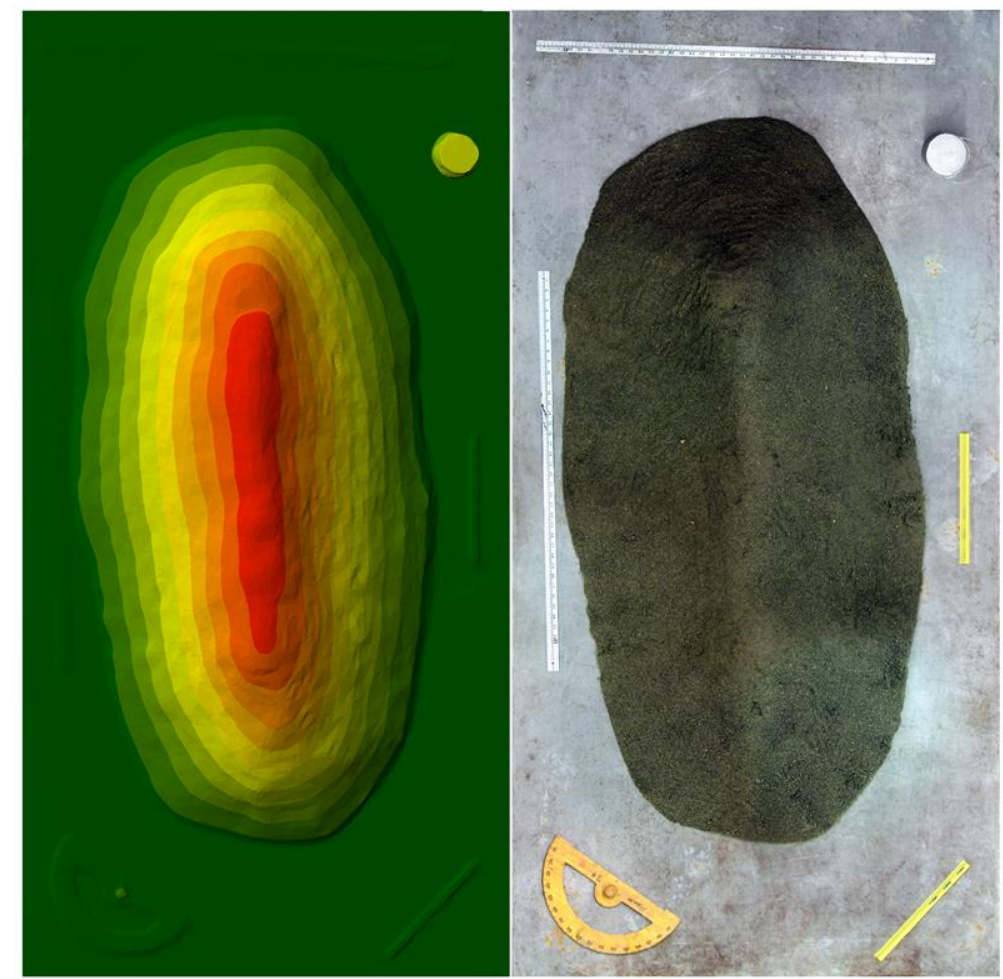

(a)

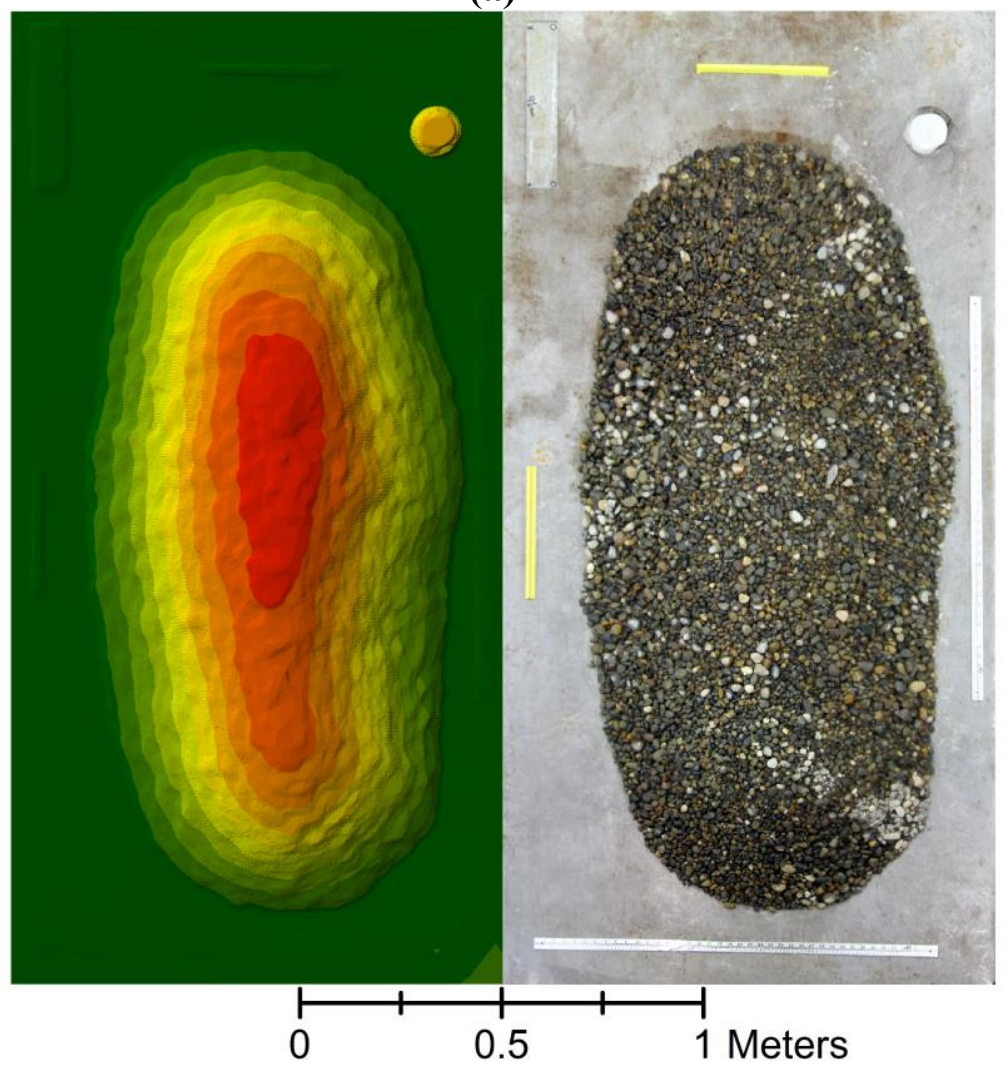

(b)

Fig. 4. Sample output for $300 \mathrm{~kg}$ piles in laboratory experiments, including DSM (left) and orthoimage mosaic (right) for a) sand, and b) gravel. Height is relative to the surface. 
298

299

Table 3

Summary of lab SfM results showing measurement accuracy and density of materials.

\begin{tabular}{|c|c|c|c|c|c|}
\hline Material & $\begin{array}{c}\text { Mass } \\
(\mathrm{kg})\end{array}$ & $\begin{array}{c}\text { Volume } \\
\left(\mathbf{m}^{\mathbf{3}}\right)\end{array}$ & $\begin{array}{l}\text { Density } \\
\left(\mathbf{k g} / \mathbf{m}^{\mathbf{3}}\right)\end{array}$ & $\begin{array}{c}\text { Relative } \\
\text { Difference in } \\
\text { Density }\end{array}$ & $\begin{array}{c}\text { Average } \\
\text { Density }\left(\mathrm{kg} / \mathrm{m}^{3}\right)\end{array}$ \\
\hline \multirow{6}{*}{ Sand } & 300 & 0.210 & 1429 & Reference & \multirow{6}{*}{$1443 \pm 35^{*}$} \\
\hline & 300 & 0.211 & 1422 & $-0.5 \%$ & \\
\hline & 250 & 0.178 & 1404 & $-1.7 \%$ & \\
\hline & 150 & 0.104 & 1442 & $0.9 \%$ & \\
\hline & 100 & 0.069 & 1447 & $1.2 \%$ & \\
\hline & 50 & 0.033 & 1515 & $6.0 \%$ & \\
\hline \multirow{6}{*}{ Gravel } & 300 & 0.170 & 1765 & Reference & \multirow{6}{*}{$1765 \pm 21^{*}$} \\
\hline & 300 & 0.167 & 1796 & $1.8 \%$ & \\
\hline & 250 & 0.142 & 1754 & $-1.0 \%$ & \\
\hline & 150 & 0.086 & 1744 & $-1.2 \%$ & \\
\hline & 100 & 0.056 & 1754 & $-0.6 \%$ & \\
\hline & 50 & 0.028 & 1786 & $1.2 \%$ & \\
\hline
\end{tabular}

* Standard deviation

300

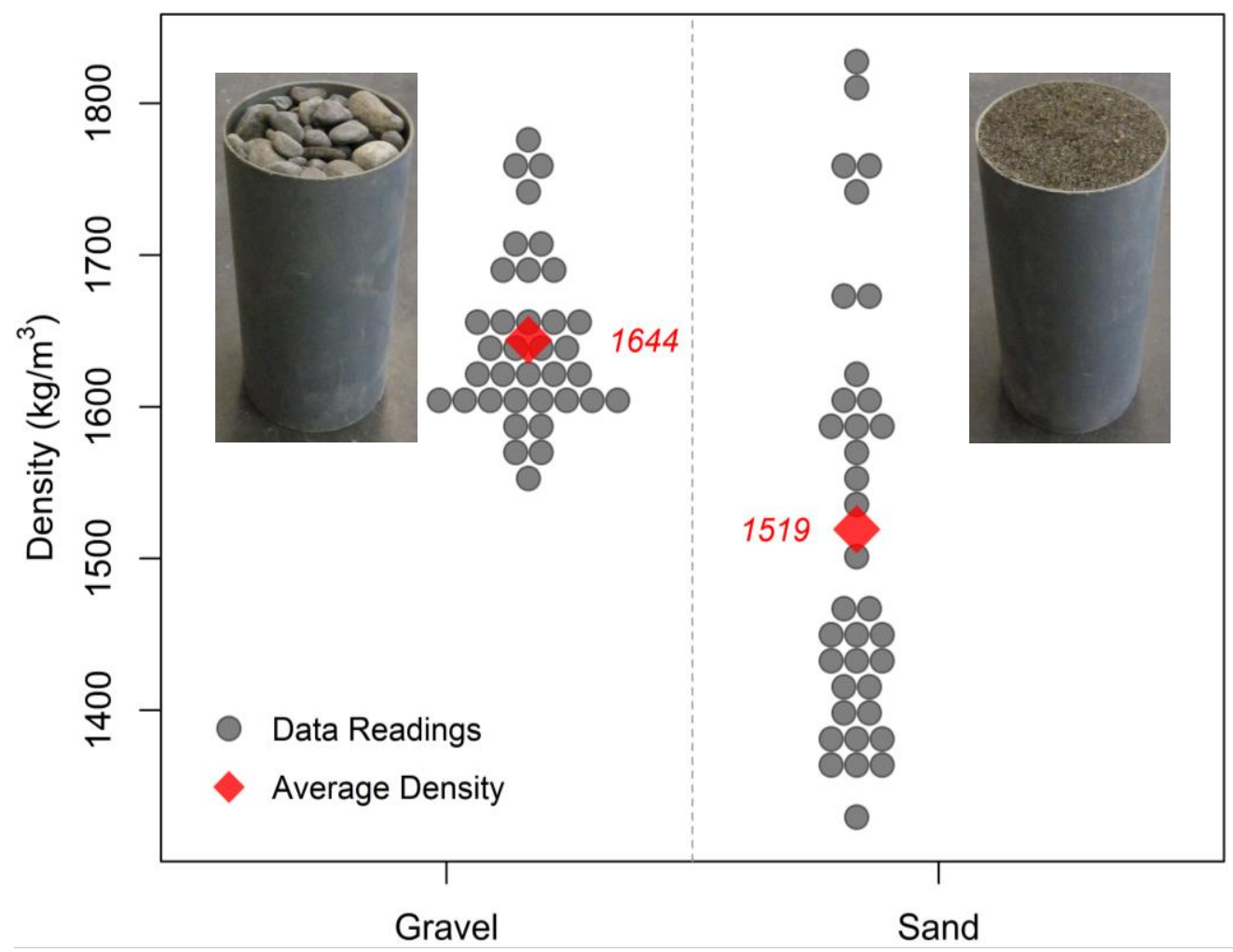

302

303
Fig. 5. Beeswarm chart of all experimental density measurements using the $4 x 8$ inch cylinder for gravel (left) and sand (right). 
304

305

306

307

308

309

310

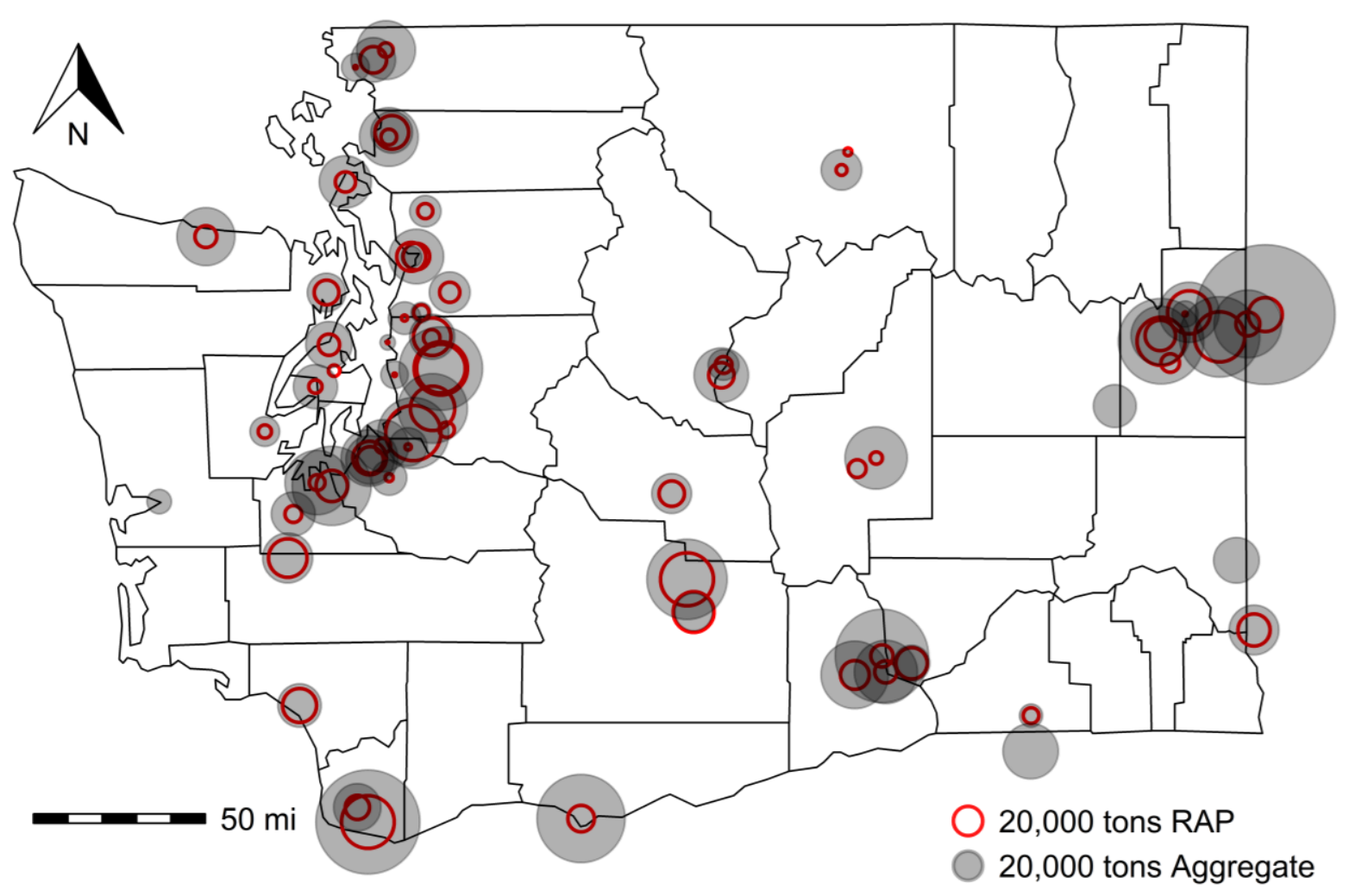

Fig. 6. Spatial distribution of aggregate and RAP stockpiles owned by hot mix asphalt plants within the state of Washington. [Area of circles are relative to weights.]

\section{Analysis and discussion}

\subsection{Area to volume scaling}

Although the exact shape of an aggregate stockpile is irregular and difficult to derive without any advanced surveying tools, some relatively simple geometric relationships can still be offered. When dividing volumes by base areas, the result will be a metric termed as average height in this study. If all stockpiles resembled the shape of a right prism, volume calculations could have been simplified to the measurements of base area and height. The average height, in this essence, transforms the irregular shape of an aggregate stockpile to a right prism with a similar base area and a constant height. An expanded database of the relationship between surface areas and volumes would be useful, as $2 \mathrm{D}$ area is relatively easy to measure.

Tucci et. al (2019) conducted a similar analysis on an aggregate quarry site of 9 stockpiles and found out that the average height of stockpiles ranges from 0.9 to 4.5 meters (compared to 2.2 to 4.7 meters found in this study) [14]. While this hypothetical height is hard to measure (requires volume and area measurements) or questionable to assume, another property of aggregate stockpiles can well substitute it. As presented in Table 2, the average heights can be related to the maximum height of any aggregate pile. This relation (average to maximum height ratio) seems to be more constrained than any other vertical property (e.g., average height) of aggregate stockpiles. This ratio took values in a range of 0.37 to 0.49 , with an average of 0.44 in our case. Such metric can be used in a variety of remote sensing applications when estimating volumes. In other words, the process of volume estimation can be summarized in three basic steps: 1) base area measurements, 2) maximum height measurement (or estimation), and 3) multiply step 1 and 2 by 
a ratio between 0.37 and 0.49 (or as recommended otherwise).

\subsection{Volume to weight conversion}

Laboratory experiments designed in this study aimed particularly at demonstrating how density of aggregate stockpiles can be measured from two fundamentally different methods. In both experiment setups, however, weight measurements were involved. In general, density of such porous and non-isotropic materials can be defined in multiple ways. In this study, however, the loose density as in the case of aggregate stockpiles in a quarry site was of interest, and the experimental plan was devised in a way to simulate the case. In this section we discuss and compile the findings from this study and claim that while density measurements are sensitive to methodology and definition, our results in part conform with the existing literature.

Direct density measurements (as depicted in Figure 5) showed that sand density tends to be more sensitive to compaction. One explanation is, as opposed to coarser aggregate sizes, finer particles can easily roll over each other and form tighter interlock under high compaction forces. This uncertainty in density values makes the conversion of volume to a weight less intuitive. However, following a statistical approach and not adhering to standard test procedures such as ASTM C29/AASHTO T19 to measure bulk density of aggregates, the method employed here intends to convey a sporadic nature rather than a deterministic value for density. In real world case of an aggregate stockpile, density might not be distributed uniformly throughout the pile either. We believe that the scatter of values observed in Figure 5 can represent how density changes throughout an actual stockpile and thus using the average appears justifiable.

Comparing the results of the two methods of measuring density explained earlier (see Table 3 and Figure 5), SfM-based density measurements fall well within the expected range. To recapitulate, densities found for sand and gravel from SfM application were in the range of 1,404 to 1,515 and 1,744 to $1,796 \mathrm{~kg} / \mathrm{m}^{3}$, respectively, while direct measurements yielded a rather similar respective range of 1,300 to 1,800 and 1,550 to $1,800 \mathrm{~kg} / \mathrm{m}^{3}$. Based on these results, we argue that accurate density estimates can be obtained from laboratory or field SfM-derived volume measurements for piles with known weights. Moreover, density estimates from the two different approaches (i.e. direct measurements and SfM photogrammetry) are consistent with the values suggested in previous studies (e.g. [24]) and EPA recommendations [28] and can be used to convert remotely measured volume of stockpiles to weights.

\subsection{Comparison to National surveys}

The National Asphalt Pavement Association (NAPA) is an organization responsible for conducting annual surveys on HMA and recycled asphalt materials inventory. In a traditional manner, NAPA sends out survey questionnaires to a representative number of asphalt plant owners to collect information about the amount of asphalt and recycled materials used and stockpiled on a yearly basis. For the case of Washington State, NAPA received responses from 33 production plants in its 2017 survey, which is around half of the sites surveyed remotely as part of the present study [30]. NAPA also estimated that 5.4 million metric tons of asphalt was produced in 2017, out of which 1.1 million metric tons were RAP. This can then be translated into a total weight of about 4.2 million tons of raw materials used in the form of aggregate and liquid asphalt. Compared to the 4.4 million tons of aggregates found here, while viewing the fact that NAPA uses an entirely different method to survey stockpile quantities, our results look promising and suggest acceptable degree of conformation. We should however point out that the quantities measured in this study 
capture the inventory of aggregate and RAP stockpiles in a given year and not necessarily the annual supply. Repeat surveys in this essence can provide more detailed information on volume changes, annual consumptions, and recourse depletion.

\subsection{Significance, limitations, and implications}

Given the time and expenditure requirements to conduct UAV surveys, an approach involving satellite remote sensing seems to be a viable alternative to field measurements; especially if quantities beyond a single corporation are desired. The UAV survey of the aggregate quarry site of this study, as an example, took approximately 3 hours to carry out, not including 2 hours of travel time. The equivalent time to remotely estimate volumes of a same quarry site would take less than half hour using Google Earth as a publicly available platform (an effort ratio of 1 to 10, not considering the image processing time). UAV surveys similar to this research study can build a foundation for future remote sensing attempts on aggregate volume calculations by providing a framework on converting base area to volume, expediting the movement towards well documented inventory of HMA supply, and eventually other industries using stockpiled materials.

Nonetheless, it must be emphasized that many assumptions were involved throughout this study which necessitate and call for future validation endeavors. One limitation of employing such surveying approach could be the unavailability of satellite images and the fact that some regions might not be fully covered, and if so, the resolutions can still be unsatisfactory. The other challenge is related to the temporal aspect of these images which are not usually spontaneous, nor taken at the same time intervals throughout the region under study. In this study, satellite images were only available for the time period between May and August. Therefore, the findings in this study pertain to a particular time frame during the entire year. This further means, due to the fact that aggregate stockpile volumes are subject to fluctuations in a given year, this study was unable to identify the total supply of aggregates. Moreover, as brought up previously, 3D simulated terrain models are not available for an entire state. However, this is a relatively newborn technology with high potential of rapid progression given the enormous amount of data produced on a daily basis.

All complications aside, the superiority of a similar database formed in this study to National survey efforts is the fact that geographic information elements are embedded as a supplementary piece. Since materials transportation can incur significant costs, this database is believed to feed sufficient input to decision makers in a statewide scale. As an example, let us assume an average trucking cost of $\$ 0.25$ per U.S. ton-mile (or about $\$ 0.18$ per metric ton-km), as discussed in the introduction. Also, assume that an average truck can load 20 tons of materials and would drive for 30 miles (about $50 \mathrm{~km}$ ) [6] for delivery. We can infer from our database that overall annual hauling cost of aggregate transportation for asphalt producers within Washington State is about $\$ 42$ million. Depending on the size of production plant, this cost ranged from about $\$ 50$ thousand to over $\$ 4$ million per an individual plant.

Beside economic factors, the environmental burden of aggregate transportation can be assessed from cradle to gate through the use of Life Cycle Assessment (LCA) techniques [31]. Similarly, performing such environmental assessments requires information on the location of which materials were originated (point of supply) and delivered (point of demand). While the results of this study can satisfy the former, linking to the latter piece anticipates further research to fully understand the demand-supply chain involved in the industry. At this point, we suffice to run some simple calculations using rule of thumb inputs for environmental impact assessment. A typical conventional heavy-duty diesel dump truck burns about $680 \mathrm{~J}$ energy in the form of fuel and emits about 56 grams $\mathrm{CO}_{2}$-eq per ton-km basis (retrieved from Greenhouse Gases, Regulated Emissions, 
416 and Energy Use in Transportation Model (GREET) [32]). Following the same assumption on 417 average hauling distance of 30 miles (about $50 \mathrm{~km}$ ), our database estimates that $200 \mathrm{TJ}$ of energy 418 is consumed in the form of diesel which emits more than 16,000 tons of $\mathrm{CO}_{2}$-eq within the State, 419 only due to aggregate transportation. Again, we estimate that, depending on facility size, 0.25 to $42020 \mathrm{TJ}$ of energy and 20 to over 1,500 tons of $\mathrm{CO}_{2}$-eq is emitted annually from aggregate 421 transportation per asphalt production plants surveyed here. It is worth mentioning, however, that 422 these estimates are based on the assumption that plants would consume as much aggregates as 423 found from the survey performed in this study.

\section{Summary and conclusions}

This study proposes a remote sensing application to estimate the statewide inventory of aggregate and RAP stockpiles in possession of asphalt plants. Information about the location of asphalt production facilities within the state of Washington was collected and organized in a database. Satellite imagery from Google Earth software along with some of its built-in measurement tools were used to identify and estimate the volume of aggregate stockpiles stored within processing sites. Although 2D measurements of base surface area is straight forward, finding out the elevation profile of aggregate stockpiles poses some serious challenges. To overcome this complication, simplistic though rational assumptions were made to come up with an average height for which when multiplied by base area would result in the volume of stockpiles (conversion of an irregular stockpile shape into a right prism). To examine and support the validity of these assumptions, two other experiments were performed to measure the volume of aggregate stockpiles at two different scales.

First, to gain insights on a real scale geometry, a camera equipped UAV was flown over an aggregate quarry site to acquire aerial images. The UAV survey documented detailed pile geometry and volume, with the ratio between volume to base surface area (average height) of $\sim 2-5$ meters. Second, a laboratory experiment involving piles of sand and gravel with known weights and physical properties was designed to estimate bulk density of each aggregate type. Close-range SfM photogrammetry techniques were used to create 3D models and measure pile volumes. Average relative error for SfM volume measurements was typically less than $2 \%$. Additionally, density of each aggregate type was directly measured by filling up a cylinder with known volume accompanied with weight measurements under a variety of compaction levels. Results from the field and laboratory experiments provided valuable constraints and insights on geometric (i.e. volume calculation) and physical properties (i.e. density measurements) of aggregate stockpiles.

Satellite imagery analysis of aggregate volumes used to produce asphalt mixtures in Washington State showed that 4.4 and 1.1 million metric tons of crushed stone and RAP, respectively, were stockpiled throughout the state in 2017 which is in an acceptable compliance with NAPA survey results. Furthermore, economic and environmental cost assessments associated with transporting these dense materials require knowledge on spatial distribution and quantities, in which remote sensing surveys can deliver both at once. It was estimated that trucking aggregate resources from plant to job sites can incur a statewide cost of about $\$ 42$ million, while consuming around $200 \mathrm{TJ}$ of energy and emitting over 16 thousand $\mathrm{CO}_{2}$-eq. However, a more extensive study on the merit of such database in conducting economic and environmental impact assessment on asphalt production industry is warranted.

To summarize, UAVs are quick, inexpensive, accurate, and safe tools to accomplish surveys in the construction industry. Having such powerful technology in hand, an inventory of a representative sample of aggregate stockpiles within an entire state can be collected. This will 
461

462

463

464

465

466

467

468

469

470

471

472

473

enable construction engineers to adopt a network-level approach into resource allocation, ultimately reaching into an equilibrium state in the demand-supply chain for aggregates, the most commonly consumed raw material in the U.S. However, with the increasing availability of highresolution satellite imagery and improved global terrain models, remote sensing techniques can potentially be substituted to extract similar measurements with improved efficiency, especially for larger inventories that extend beyond a single owner entity.

\section{Acknowledgments}

Authors would like to thank Mr. David Bell and Lakeside Industries for his coordination with the aggregate quarry plant to make the UAV survey possible.

\section{Formatting of funding sources}

This research did not receive any specific grant from funding agencies in the public, commercial, or not-for-profit sectors.

\section{References}

[1] G. R. Matos, "Use of raw materials in the United States from 1900 through 2014," U.S. Geological Survey (USGS), Reston, VA, 2017.

[2] USGS, "Mineral Commodity Summaries 2019," U.S. Geological Survey, 2019.

[3] EPA, "Construction and Demolition Debris Generation in the United States, 2014," 2 December 2016. [Online]. Available: https://www.epa.gov/sites/production/files/201612/documents/construction_and_demolition_debris_generation_2014_11302016_508.pdf.

[4] EPA, "Advancing Sustainable Materials Management: 2015 Fact Sheet," U.S. Environmental Protection Agency, Washington, D.C., 2018.

[5] J. C. Willett, "2015 Minerals Yearbook: Stone, Crushed [Advanced Release]," U.S. Geological Survey, 2017.

[6] G. R. Robinson and W. M. Brown, "Sociocultural Dimensions of Supply and Demand for Natural Aggregate - Examples from the mid-atlantic Region, United States," U.S. Geological Survey, 2002.

[7] M. Yakar and H. M. Yilmaz, "Using in Volume Computing of Digital Close Range Photogrammetry," The International Archives of the Photogrammetry, Remote Sensing and Spatial Information Sciences, vol. XXXVII, no. Part B3b, pp. 119-124, 2008.

[8] R. Wróżyński, . K. Pyszny, M. Sojka, C. Przybyła and S. Murat-Błażejewska, "Ground Volume Assessment using 'Structure from Motion' Photogrammetry with a Smartphone and a Compact Camera," Open Geosciences, vol. 9, no. 1, pp. 281-294, 2017.

[9] R. K. Rhodes, "UAS as an Inventory Tool: A Photogrammetric Approach to Volume Estimation," University of Arkansas, Fayetteville, 2017.

[10] H. M. Yilmaz, "Close Range Photogrammetry in Volume Computing," Experimental Techniques, pp. 48-54, 2010.

[11] J. H. Crotty, B. Ernst, A. Machele and J. Lategan, "Measuring Rock Dumps from Space? How New Technology Could Change the Way We Measure Rock Dumps and Tailings Dams," in The 4th International Platinum Converence, Platinum in Transition 'Boom or 
Bust', Sun City, Rustenburg, South Africa, 2010.

[12] K. Whitehead, C. H. Hugenholtz, S. Myshak, B. Owen, A. LeClair, A. Tamminga, T. E. Barchyn, B. Moorman and B. Eaton, "Remote Sensing of the Environment with Small Unmanned Aircraft Systems (UASs), Part 2: Scientific and Commercial Applications," Journal of Unmanned Vehicle Systems, vol. 2, no. 3, pp. 86-102, 2014.

[13] A. Zylka, "Small Unmanned Aerial Systems (sUAS) for Volume Estimation," UVM Honors College, 2014.

[14] G. Tucci, A. Gebbia, A. Conti, L. Fiorini and C. Lubello, "Monitoring and Computation of the Volumes of Stockpiles of Bulk Material by Means of UAV Photogrammetric Surveying," Remote Sensing, vol. 11, no. 12, 2019.

[15] C. H. Hugenholtz, J. Walker, O. Brown and S. Myshak, "Earthwork Volumetrics with an Unmanned Aerial Vehicle and Softcopy Photogrammetry," Journal of Surveying Engineering, vol. 141, no. 1, 2015.

[16] C. Arango and C. A. Morales, "Comparison Between Multicopter Uav and Total Station for Estimating Stockpile Volumes," International Archives of the Photogrammetry, Remote Sensing and Spatial Information Sciences, Vols. XL-1/W4, pp. 131-135, 2015.

[17] P. L. Raeva, S. L. Filipova and D. G. Filipov, "Volume Computation of a Stockpile - A Study Case Comparing GPS and UAV Measurements in an Open Pit Quarry," The International Archives of the Photogrammetry, Remote Sensing and Spatial Information Sciences, Vols. XLI-B1, 2016.

[18] K. Julge, A. Ellmann and R. Kook, "Unmanned Aerial Vehicle Surveying for Monitoring Road Construction Earthwork," The Baltic Journal of Road and Bridge Engineering, vol. 4, no. 1, pp. 1-17, 2019.

[19] J. Lawrence and G. Letham, "Mineral Stockpile Volumes from UAV Photogrammetry and Terrestrial Lidar," Photogrammetric Engineering \& Remote Sensing, vol. 84, no. 6, pp. 333-335, 2018.

[20] D. E. Shean, O. Alexandrov, Z. M. Moratto, B. E. Smith, I. R. Joughin, C. Porter and P. Morin, "An automated, open-source pipeline for mass production of digital elevation models (DEMs) from very-high-resolution commercial stereo satellite imagery," ISPRS Journal of Photogrammetry and Remote Sensing, vol. 116, pp. 101-117, 2016.

[21] P. Dong, C. Wang and J. Ding, "Estimating Glacier Volume Loss using Remotely Sensed Images, Digital Elevation Data, and GIS Modeling," International Journal of Remote Sensing, vol. 34, no. 24, pp. 8881-8892, 2013.

[22] J. F. Crétaux, R. Abarca-del-Río, M. Bergé-Nguyen, A. Arsen, V. Drolon, G. Clos and P. Maisongrande, "Lake Volume Monitoring from Space," Surveys in Geophysics, vol. 37, no. 2, pp. 269-305, 2016.

[23] A. Bilous, V. Myroniuk, D. Holiaka, S. Bilous, L. See and D. Schepaschenko, "Mapping Growing Stock Volume and Forest Live Biomass: A Case Study of the Polissya Region of Ukraine," Environmental Research Letters, vol. 12, 2017.

[24] X. Wang, Z. Al-Shabbani, R. Sturgill, A. Kirk and G. B. Dadi, "Estimating Earthwork Volumes Through Use of Unmanned Aerial Systems," Transportation Research Record: Journal of the Transportation Research Board, vol. 2630, pp. 1-8, 2017.

[25] M. Zokaei Ashtiani, S. T. Muench, D. Gent and J. S. Uhlmeyer, "Application of Satellite 
Imagery in Estimating Stockpiled Reclaimed Asphalt Pavement (RAP) Inventory: A Washington State Case Study," Construction and Building Materials, vol. 217, pp. 292300, 2019.

[26] WSDOT, "Construction Manual," Washington State Department of Transportation (WSDOT), Olympia, WA, 2019.

[27] K. Skorseth and A. A. Selim, "Gravel Roads Maintenance and Design Manual," Federal Highway Administration (FHWA), 2000.

[28] EPA, "Standard Volume-to-Weight Conversion Factors," 28 February 2006. [Online]. Available:

https://archive.epa.gov/epawaste/conserve/smm/wastewise/web/pdf/conversions.pdf. [Accessed 2 July 2019].

[29] F. Aguera-Vega, F. Carvajal-Ramirez and P. Martinez-Carricondo, "Assessment of Photogrammetric Mapping Accuracy Based on Variation Ground Control Points Number using Unmanned Aerial Vehicle," Measurement, vol. 98, pp. 221-227, 2017.

[30] B. A. Williams, A. Copeland and T. C. Ross, "Asphalt Pavement Industry Survey on Recycled Materials and Warm-Mix Asphalt Usage: 2017," National Asphalt Pavement Association (NAPA), Lanham, MD, 2018.

[31] A. Mukherjee, "Life Cycle Assessment of Asphalt Mixtures in Support of an Environmental Product Declaration," National Asphalt Pavement Association (NAPA), Lanham, MD, 2016.

[32] GREET, "The Greenhouse Gases, Regulated Emissions, and Energy Use in Transportation Model," 2018. [Online]. Available: https://greet.es.anl.gov. [Accessed February 2020]. 